\title{
SMARTPHONE ADDICTION AND FAMILY COMMUNICATION IN
}

\section{ADULTS}

Uzma Jabeen $^{1 *}$, Humaira Sarvat ${ }^{2}$, Zunaira Hashmi $^{3}$

${ }^{1 *}$ Assistant Professor of Psychology, Government Post Graduate Islamia College, Cooper Road, Lahore, Pakistan;

${ }^{2}$ Assistant Professor of English, Government College for Women University, Faisalabad, Pakistan; ${ }^{3} \mathrm{BS}$, Psychology

Student, Government Post Graduate Islamia College, Cooper Road, Lahore, Pakistan.

Email: ${ }^{1 *}$ uzmajabeengcuf@gmail.com, ${ }^{2}$ humairabhatti05@gmail.com, ${ }^{3}$ hashmizuni02@gmail.com

Article History: Received on $21^{\text {st }}$ May 2021, Revised on $17^{\text {th }}$ June 2021, Published on $26^{\text {th }}$ June 2021

\section{Abstract}

Purpose of the study: This quantitative research investigates the effects of smartphone addiction on family communication.

Research Methodology: The sample size (N=200) consists of 100 males and 100 females. The participants have been divided into three groups according to age, age group 18-20, age group 21-23, and age group 24-25. The sample has been selected by the purposive sampling technique. Smartphone Addiction Scale- Short Version (SASS-SV)has been used to measure smartphone addiction and Family Communication Scale (FCS) assesses the family communication of adults. For statistical analysis Statistical Package for Social Sciences(SPSS) version 23 software has been used. The relationship has been assessed using Pearson correlation and an independent sample t-test has been used to find meaningful differences.

Main findings: The study concludes that there is no significant effect of smartphone addiction on family communication. Moreover age group (18-20) is more addicted to the smartphone than the other age groups.

Application of the Study: The study will provide researchers with enough data and information related to smartphone addiction and family communication. Findings will also enable them to further explore the long-term use of smartphones in the joint family system.

Innovation of the Study: Joint family system is the norm in Pakistan whose major part of the population comprises youth, ages between 18-20 years. No research on smartphone addiction in the perspective of family communication in a joint family system has yet been conducted in Pakistan to my knowledge.

Keywords: Smartphone Addiction, Family Communication, Age Group, Relationship, Statistical Analysis.

\section{INTRODUCTION}

A smartphone is a cellular telephone with an integrated computer and other features not originally associated with telephones e.g. web browsing, and the ability to run software applications (Provazza, 2019). Some key features of smartphones are a camera, multimedia player, internet browser, navigation system, and e-mail service, social networking, and game-playing (Provazza, 2019). It distracts us from the present moment and disrupts relationships, which lead to couples break- up, destabilizing the parent-child bond, and widening the generation gap, leading to utter deterioration of social values (Sumati, 2016).

According to Statista 2019, the current number of smartphone users in the world today is 3.5 billion which means $45.04 \%$ of the world's population owns a smartphone (Turner, 2020). The citizens of Pakistan, like people in other countries, are also consumed in this technological revolution. According to Pakistan Telecommunication Authority (PTA), there are 164 million cellular subscribers among which 77 percent of users are youth.

\section{Smartphone Addiction}

Smartphone addiction is the excessive use of smartphones in a way that is difficult to control and its influence extends to other areas of life in a negative way (Park \& Lee, 2012). It is a common problem among adults worldwide and manifests itself in the excessive usage of their phones, while studying, driving, and social gatherings, and even sleeping (Harwood, Dooley, Scott, Joiner, 2014).

According to the statistics of the website bankmycell 2019, the average smartphone user checks his phone 63 times a day and $86 \%$ of users check their smartphone during the conversation with friends or family. $87 \%$ of people check their phone within one hour of waking up or going to sleep. $69 \%$ of smartphone users check their phones within 5 minutes of waking up in the morning. The average time spent on smartphones is 2 hours and 51 minutes a day. Among the users between ages 18-29 years old, 22 percent check their phones every few minutes and 51\% check their smartphone a few times within an hour (Turner,2020).

Researchers have found that smartphone addicts show the same symptoms of behavioural addiction (Bian\& Leung, 2014). Behavioural addictions or non-substance addictions are a set of behaviours that a person becomes dependent on and craves (Smith, 2018). It follows the same pattern as substance-based addictions. The essential feature of behavioral 
addictions is the failure to resist an impulse, drive, or temptation to perform an act that is harmful to the person (Ruscitella, 2020).

\section{Symptoms}

Symptoms of smartphone addiction include craving, withdrawal, intolerance, daily-life disturbance, and preference of cyberspace-oriented relations (Kwon, Lee, Won, Park, Min, 2013). Some other symptoms are anxiety and disorientation, excessive phone use, the manifestation of negative emotions when phone usage is reduced, inability to refrain from using smartphones in inappropriate situations, and productivity loss(Park \& Lee, 2012). Bian\& Leung (2014) believe that disregard of harmful consequences, preoccupation, and inability to control craving, productivity loss, feeling anxious and lost are some of the deadliest symptoms of the smartphone.

Based on a few previous types of research and articles, the following are some of the main reasons for smartphone addiction:

- Smartphones upgrade constantly introducing new functions, that attract people to explore and experience new things, lead to excessive use of newer technologies(Kiran, Sanjana \& Naik, 2019).

- Applications are designed using marketing and designing techniques that attract the users and keep them engaged which causes the attachment to one's phone (Kiran, Sanjana \& Naik, 2019).

- From texting to keeping work-related files, the multi-faced functionality of smartphones also leads to excessive usage. Moreover, access to social networking sites to make new friendships also tends to form an addiction (Kiran, Sanjana \& Naik, 2019).

Psychological effects of smartphone addiction include anxiety when people cannot receive constant updates and interaction from friends (Hawkins,2014), experiencing nomophobia when the smartphone is not nearby (Hawkins, 2014), depression caused by excessive texting, social networking, gaming, viewing video clips (Pearson \& Hussain, 2016), poor sleep quality due to the blue light that emits from mobile and push back sleep time (Patel, 2017), stress caused by smartphones (Turner, 2020).

Akhlaq, Malik, \& Khan (2013)defined families as "one of the fundamental units of society and are the building blocks of social structures and organizations in every culture". There are six types of family structures named as nuclear family, extended or joint family, adoptive family, single-parent family, stepfamily, grandparent family. However, the first two are seen in Pakistan (Rasheed, 2015).

In Pakistan, 'family first' is a fundamental concept. A joint family consists of grandparents, uncles, aunts, cousins, and grandchildren (Rasheed, 2015). A nuclear family consists of a father, a mother, and their biological or adoptive children. The nuclear family system is considered an ideal type in America but not in Pakistan (Akhlaq, Malik, \& Khan, 2013).

\section{Family Communication}

Family communication can be defined as all interactive behaviors of family members that establish family roles, maintain family rules, accomplish family functions, and sustain behavioral patterns in families (Vangelisti, 2004).

Family communication pattern theory focuses on parent-child communication concerned with establishing a shared social reality. Family communication patterns are ways by which families establish social realities for themselves (Koerner \& Fitzpatrick, 2006). Later on, Fitzpatrick and Ritchie (1994) redefined this theory and renamed dimensions as conversation orientation (previously called concept orientation) and conformity orientation (previously called socioorientation). This is known as the Revised Family Communication Patterns (RFCP) instrument used to measure these dimensions more accurately.

Two dimensions that determine family communication patterns are conversation orientation, the degree to which family members are encouraged to discuss a variety of topics and engage in spontaneous interactions, and conformity orientation that is the degree to which families create a climate that stresses homogeneity of attitudes, values, and beliefs (Koerner \& Fitzpatrick, 2006).

These two dimensions give rise to four possible communication patterns that are consensual, pluralistic, protective, and laissez-fair. Consensual families encourage their children to speak up freely but also expect them to agree and follow parent's decisions. Pluralistic families allow open talk, without restrictions and parents do not strive to control. Protective families do not allow open communication. Laissez-faire families rarely engage in conversation, limited to a few topics and children make their decisions and parents show little to no interest in them (Koerner \& Fitzpatrick, 2006).

The Circumplex Model of Marital and Family Systems described by Olson and DeFrain as "a graphic representation of dynamic relationships within families" depicts family functioning in three dimensions: cohesion (emotional bonding between family members), flexibility (amount of change in its leadership, role relationships and relationship rule) and communication (making information, ideas, thoughts, and feelings known among family members). Family communication is crucial as it maintains a balance between cohesion and flexibility (Olson, 2000). 


\section{Rationale and Objective of the study}

This study aims at defining the importance of family communication in a collectivistic society like Pakistan. The study will enable adults to understand the aversive nature of smartphones and the importance of direct communication with family.

\section{Objectives of study}

- To investigate smartphone addiction in males and females.

- To find out the levels of family communication of adults.

- To find out the levels of smartphone addiction in different age groups.

- To find the relationship between smartphone addiction and family communication.

\section{LITERATURE REVIEW}

Seo and Bang (2017) measured smartphone addiction in nursing students and determined the relationship between smartphone addiction and family communication. Research suggested factors behind smartphone addiction like smartphone usage time, life stress, the importance of smartphones in their lives, and family communication, and statistical analysis showed that smartphone addiction correlated significantly with life stress and negatively correlated with family communication $(\mathrm{r}=-.26)$.

SinsomsackandKulachai (2018) studied the impacts of smartphone addiction on mental health, family relationships, social relationships, and academic performance in high school students. Results indicated a positive relationship between mood disorders and smartphone addiction. Results also revealed that smartphone addicts' students have poor social interaction and also a poor relationships with their families. They rarely communicate with family members since they are busy with smartphones. The study also revealed negative consequences of smartphone addiction on health like neck pain, finger pain. Smartphone addict students also have poor academic performance.

Lee (2016) researched to understand the effect of parent-son/daughter communications on the addiction to smartphones, with stress level, self-control, and self-efficacy as the mediator. His study showed that smartphone addiction had negative correlations with parent-son/daughter communication, self-control, and self-efficacy but had positive correlations with stress levels. In addition, parent-son/daughter communication influenced the degree of smartphone addiction, with stress level, self-control, and self-efficacy as the mediator.

Bianand Leung (2014) research shows that the symptoms of smartphone addiction are significantly and negatively related to the level of face-to-face communication. Results also showed that smartphone addicts scored high on loneliness and shyness. Using exploratory faction analysis, they identified five symptoms of addiction like disregard of harmful consequences, preoccupation, inability to control craving, productivity loss, and feeling anxious and lost.

Pugh (2017) investigated the possible relationship between smartphone addiction, self-esteem, social anxiety, gender, and age. Analysis revealed no significant relationship between smartphone addiction, self-esteem, and social anxiety. However, age and gender differences were found between the variables examined. Females scored higher on smartphone addiction and social anxiety than males. A negative relationship was found between smartphone addiction and age.

Gladden (2016) investigated the daily usage of smartphones by individuals in different age groups and also its effects on individuals in real-life social interactions. The results showed that the majority of respondents spend 3-5 hours a day using their smartphones, with $75 \%$ of respondents saying that they mostly used Instagram and Facebook. The conclusion indicated that individuals with the age range 18-30 are the ones most affected in their social interactions because they relied on smartphones.

Pearson and Hussain (2016) examined the relationship between narcissism, personality, and smartphone addiction. Analysis revealed a positive relationship between smartphone addiction and narcissism personality and daily use of smartphones and length of ownership. The study also revealed that age and narcissism, openness, neuroticism personalities were linked to smartphone addiction.

Tajalli and Zarnaghash (2017) investigated the role of family communication patterns including consensual, pluralistic, protective, and laissez-faire, on internet addiction. Their study showed that children with laissez-faire family patterns have the highest levels of using the internet. These families rarely engage in conversation and children use the internet as an escape from these conflicts. In contrast, pluralistic families, high on conversation orientation, scored significantly lowest on internet use. These families allow children to express their thoughts freely. It prevents them from psychological problems and internet addiction. The analysis further showed a positive relationship between conversation orientation and a negative relationship of conformity orientation with Internet addiction. This research also indicated problems that are both causes and effects of internet addiction such as lack of family responsibility, absence of family support, family isolation, failure in job and education, and the feeling of worthlessness. 


\section{Hypotheses}

- There would be a relationship between smartphone addiction and family communication.

- Males are more likely to be addicted to their smartphones than females.

- The age group 18-20 is more likely to be addicted to their smartphones than the age group 21-23.

\section{METHODOLOGY}

\section{Participants}

The present study examined the relationship between smartphone addiction and family communication. A sample of 200 participants consisted of (100 males and 100 females) with the age range 18-25 years who owned their smartphones was selected. Data were collected from residents of Lahore only.

\section{Sampling Strategy}

A purposive sampling strategy was used to collect data.

\section{Research Design}

A quantitative research method was used to find the relationship between smartphone addiction and family communication. A survey research design was used to collect data.

\section{Instruments used}

- Smartphone Addiction Scale-Short Version (SAS-SV).

- Family Communication Scale.

- Smartphone Addiction Scale-Short Version.

- Smartphone Addiction Scale-Short Version (SAS-SV) developed by Kwon et al (2013) is a revised version of the Smartphone Addiction Scale (SAS). It has Cronbach's alphas of 0.911.

\section{Family Communication Scale}

Developed by Olson and Barnes, Family Communication Scale consists of 10 items that are used to measure family communication. It has Cronbach's alphas of 0.60 .

\section{Statistics}

For statistical analysis, SPSS version 23 was used. To find a correlation between smartphone addiction and family communication Pearson correlation ' $r$ ' was used. An independent sample t-test was used to check the mean difference between the two variables.

\section{RESULTS}

Table 1: Pearson correlation between variables

\begin{tabular}{llllllllll}
\hline & $\mathrm{M}$ & $\mathrm{SD}$ & 1 & 2 & 3 & 4 & 5 & 6 & 7 \\
\hline 1 Age & 1.77 & .69 & - & & & & & & \\
2 Gender & 1.50 & .50 & -.043 & - & & & & & \\
3 Subjects & 1.41 & .49 & .116 & -.366 & - & & & & \\
4 Family System & 1.39 & .49 & -.027 & .174 & -0.29 & - & & & \\
5 Family members & 1.90 & .80 & .045 & -.054 & .165 & .357 & - & & \\
6 Smartphone Addiction & & & -.02 & .059 & -.06 & .048 & -.043 & - & \\
7 Family Communication & & & -.026 & .033 & .048 & -.147 & -.002 & .140 & 1 \\
\hline
\end{tabular}

Source: Authors

Note. $\mathrm{M}=\mathrm{Mean}, \mathrm{S} . \mathrm{D}=$ Standard Deviation

The results indicated that there is no significant relationship between smartphone addiction and family communication $(\mathrm{r}=.14)$. It was observed that fewer participants scored higher on the smartphone addiction scale. Therefore, it did not affect the family communication significantly.

Table 2: Level of smartphone addiction in males and females

\begin{tabular}{lccccccc}
\hline Gender & Female & & Male & t & sig & df \\
& M & S.D & M & S.D & & & \\
\hline Smartphone addiction & 34.67 & 9.28 & 35.72 & 8.61 & -.829 & .408 & 198 \\
\hline
\end{tabular}


Source: Authors

Note. $\mathrm{M}=$ Mean, $\mathrm{S} . \mathrm{D}=$ Standard Deviation, $\mathrm{t}=\mathrm{t}$ statistics, sig= significant level, $\mathrm{d} . \mathrm{f}=$ degree of freedom.

In terms of gender, results revealed that males are slightly more addicted to their smartphones than females.

Table 3: Smartphone addiction and family communication among age group 18-20 and age group 21-23

\begin{tabular}{lcccccccc}
\hline Age Groups & \multicolumn{2}{c}{$18-20$} & \multicolumn{2}{c}{$21-23$} & t & sig & df \\
& M & S. D & M & S. D & & & \\
\hline Smartphone Addiction & 35.69 & 9.39 & 34.64 & 8.87 & .033 & .974 & 104 & \\
\hline
\end{tabular}

Source: Authors

Note. $\mathrm{M}=$ Mean, $\mathrm{S} . \mathrm{D}=$ Standard Deviation, $\mathrm{t}=\mathrm{t}$ statistics, sig= significant level, $\mathrm{d} . \mathrm{f}=$ degree of freedom.

Results indicate that the age group 18-20 is more addicted to their smartphones than the age group 21-23.

\section{DISCUSSION}

No significant relationship was observed between smartphone addiction and family communication in the present study. As fewer participants scored higher on the smartphone addiction scale, therefore, it did not affect the family communication significantly. It contradicts with the previous study where a negative relationship was observed between smartphone addiction and family communication (Seo \& Bang, 2017). A similar study revealed poor family relationships due to smartphone usage as smartphone addicts rarely communicate with other family members since they always pay attention to a smartphone (Sinsomsack \& Kulachai, 2018). As this is an emerging field of study, not enough data is available to support finding but a similar study revealed a negative correlation between parent-son/daughter communication and smartphone addiction (Lee, 2016). In Pakistani culture, large family sizes and adults living with parents may act as protectors against smartphone addiction. However, no evidence in favor of our research was found and further research is required to elucidate the relationship between smartphone addiction and family communication. Results also indicate males are slightly more addicted to their smartphones than females. This finding supports a previous study that males use more smartphone apps and are more prone to smartphone addiction as compared to females (Bisen\& Deshpande, 2016). However, another study found that females score higher on smartphone addiction compare to males (Demirci, Orhan, Demirdas, Akpinar \& Sert, 2014). Pugh (2017) also showed in his research that females have a higher level of smartphone addiction. It was also observed that age group 18-20 is more addicted to their smartphones than age group 21-23 that supports the previous study that age group 18-20 use smartphones for socialization and are more addicted to them (Zencirci, Aygar, Göktaș, Önsüz, Alaiye\&Metintaș, 2016). A qualitative study also supports this finding that the age group 18-30 have more reliance on smartphones as compared to other age groups (Gladden, 2016). But another research found that smartphone addiction is more prevalent in the age group 10-20 as compared to the age group 20-30 years (Süt, Kurt, Uzal, Özdilek, 2016). However, a negative correlation was found between age and smartphone addiction, as age increases smartphone addiction decreases (Pugh, 2017).

\section{CONCLUSION}

The current study aimed to explore the relationship between smartphone addiction and family communication and found that there was no significant relationship between the two variables. To our best knowledge, only one study has investigated the relationship between these two variables. Future studies should look at the relationship of smartphone addiction with family communication to find enough evidence to support the result. Further, it was found that young adults of age 18-20 years tend to exhibit smartphone addiction more forcefully as compared to the age group 20-23 and 24-25. Contrary to previous studies, the present study found that males were more addicted to smartphones than females. This may be due to cultural differences.

\section{RECOMMENDATIONS}

Further researches are required to study this emerging field of study. This will enable researchers to have enough data and information related to smartphone addiction and family communication. The sample size should be large enough to represent the population so the results can be generalized. A few more dimensions can be explored in future researches like factors that affect family communication. The findings of this study will enable people to become more aware of smartphone addiction.

\section{LIMITATIONS}

- The sample size was small and data was collected from residents of Lahore only. Therefore, results cannot be generalized to the whole population.

- Data was collected in a limited time. An extensive period is required to understand this emerging field of study.

- The sample was selected using purposive sampling so everyone did not have the chance to be a part of the study. 


\section{AUTHOR CONTRIBUTION}

Miss Uzma Jabeen does the analytical part of the paper whereas Dr. Humaira does the write-up of the study and Zunaira Hashmi has helped in data collection. Every author has a significant contribution to the present article.

\section{REFERENCES}

1. Akhlaq, A., Malik, N. I.,\& Khan, N. A. (2013). Family communication and family system as the predictors of family satisfaction in adolescents. Science Journal of Psychology, 2013, 06.

2. Bian, M., \& Leung, L. (2014). Smartphone addiction: Linking loneliness, shyness, symptoms and patterns of use to social capital. Media Asia, 41(2), 159-176. https://doi.org/10.1080/01296612.2014.11690012

3. Bisen, S., \& Deshpande, Y. (2016). An analytical study of smartphone addiction among engineering students: A gender differences. The International Journal of Indian Psychology, 4(1), 70-83.

4. Demirci, K., Orhan, H., Demirdas, A., Akpinar, A., \&Sert, H. (2014). Validity and reliability of the Turkish Version of the Smartphone Addiction Scale in a younger population. Klinik PsikofarmakolojiBülteni-Bulletin of Clinical Psychopharmacology, 24(3), 226-234. https://doi.org/10.5455/bcp.20140710040824

5. Fitzpatrick, M. A., \& Ritchie, L. D. (1994). Communication schemata within the family: Multiple perspectives on family interaction. Human Communication Research, 20(3), 275-301. https://doi.org/10.1111/j.14682958.1994.tb00324.x

6. Gladden, D. J. (2018). The Effects of Smartphones on Social Lives: How They Affect OurSocial Interactions and Attitudes. OTS Master's Level Projects \& Papers. 586. https://digitalcommons.od u.edu/ots masters projects/586.

7. Harwood, J., Dooley, J. J., Scott, A. J., \&amp; Joiner, R. (2014). Constantly connected-The effects of smart devices on mental health. Computers in Human Behavior, 34, 267- 272. https://doi.org/10.10 16/j.chb.2014.02.006

8. Hawkins, A. (2014). 5 Seriously bad side effects of your smartphone addiction. Retrieved on April 29, 2021, fromhttps://www.goodhousekeeping.com/health/wellness/a24269/smartphone-syndromes/.

9. Kiran, S., Sanjana, J., \& Reddy, N. J. (2019). Mobile Phone Addiction: Symptoms, Impacts and Causes-A Review. In Int Conf Trends Ind Value Eng Bus Soc Innov, 81.

10. Koerner, A. F., \& Fitzpatrick, M. A. (2006). Family communication patterns theory: A social cognitive approach. Engaging theories in family communication: Multiple perspectives. Sage Publications, 50-55. https://doi.org/10.4135/9781452204420.n4

11. Kwon, M., Lee, J. Y., Won, W. Y., Park, J. W., Min, J. A., Hahn, C., \&amp; Kim, D. J. (2013). Development and validation of a smartphone addiction scale (SAS). PloS one, 8(2). https://doi.org/10.137 1/journal.pone.0083558

12. Lee, H. S. (2016). A convergence study the effect of college students\&\#39; parent-son/daughter communication on addiction to smartphones: Focused on the mediated effect of stress level, self-control and selfefficacy. Journal of the Korea Convergence Society, 7(4), 163-172. https://doi.org/10.1520 7/JKCS.2016.7.4.163

13. Olson, D. H. (2000). Circumplex Model of Marital and Family Systems. Journal of Family Therapy, 22(2), 144-167. https://doi.org/10.1111/1467-6427.00144

14. Park, N., \& Lee, H. (2012). Nature of youth smartphone addiction in Korea. Journal of Communication Research, 51(1), 100-132.

15. Patel, R. R. S., \& FAPA, O. (2015). Smartphone use before bedtime might impact sleep and daytime tiredness. Retrieved on April 29, 2021, from https://u.osu.edu/emotionalfitness/2015/06/17/cell-phone-use-beforebedtime-might-impact-sleep-and-daytime-tiredness/.

16. Pearson, C., \& Hussain, Z. (2016). Smartphone addiction and associated psychological factors.Addicta:The Turkish Journal of Addictions, 3(2), 1-15. https://doi.org/10.15805/addicta.2016.3.0103

17. Provazza, A. (October 2019). Smartphone. Retrieved on April 29, 2021 from https://searchmobilecomput ing.techtarget.com/definition/smartphone.

18. Pugh, S. (2017). Investigating the relationship between smartphone addiction, social anxiety, self-esteem, age \&; gender. (BA Hons in Psychology thesis). Dublin, Dublin. Business School. Retrieved on April 29, 2021, from https://esource.dbs.ie/handle/10788/3329.

19. Ruscitella, S. (May 2020). Behavioural Addictions. Retrieved on April 29, 2021, from https://quizlet.com/ 506364294/behavioral-addictions-flash-cards/.

20. Rasheed, S. A. (2015). Why joint family system is best to bring up children. Retrieved on April 29, 2021, from https://nation.com.pk/14-May-2015/why-the-joint-family-system-is-the-best-to-bring-up-children?show=850.

21. Seo, G. S., \&amp; Bang, S. Y. (2017). The relationship among smartphone addiction, life stress, and family communication in nursing students. Journal of the Korea Academia-Industrial cooperation Society, 18(4), 398407.

22. Sinsomsack, N., \&Kulachai, W. (2018, March). A study on the impacts of Smartphone addiction.In 15th International Symposium on Management (INSYMA 2018). Atlantis Press. https://doi.org/10.2991/insyma18.2018 .61 
23. Smith, C. (October 2018). Behavioural addictions and what are they and how does one develop.Retrieved on April 29, 2021, fromhttps://www.addictioncenter.com/community/behavioral-addictions/.

24. Sumati, Y. (2016). Overuse/Misuse of smartphones and Family Integration.InternationalJournal on Recent and Innovation Trends in Computing and Communication, 4(8), 27-32.

25. Süt, H. K., Kurt, S., Uzal, Ö., \&Özdilek, S. (2016). Effects of smartphone addiction level on social and educational life in health sciences students. Eurasian Journal of Family Medicine, 5(1), 13-19

26. Tajalli, F., \&Zarnaghash, M. (2017). Effect of family communication patterns on Internet addiction. Practice in Clinical Psychology, 5(3), 159-166. https://doi.org/10.18869/acadpub.jpcp.5.3.159

27. Turner, A. (2020). How many phones are in the world? Retrieved on April 29, 2021, from https://www.bankmycell.com/blog/how-many-phones-are-in-the-world.

28. Turner, A. (2020). Smartphone addiction facts \&amp; phone usage statistics. Retrieved on April 29, 2021, from https://www.bankmycell.com/blog/smartphone-addiction/.

29. Vangelisti, A. L. (Ed.). (2004). LEA\&\#39; s communication series. Handbook of family communication. New Jersey, London: Lawrence Erlbaum Associates Publishers.

30. Zencirci, S. A., Aygar, H., Göktaş, S., Önsüz, M. F., Alaiye, M., \&amp;Metintaş, S. (2018). Evaluation of smartphone addiction and related factors among university students. International Journal of Research in Medical Sciences, 6(7), 2210-2216. https://doi.org/10.18203/2320-6012.ijrms20182805 